\title{
Destination Bulgaria on the Silc Road - Opportunities and Challenges
}

\author{
Prof. PhD Stoyan Marinov \\ University of Economics - Varna, Varna, Bulgaria \\ s.marinov@ue-varna.bg \\ Chief Assistant, PhD Krasimira Yancheva \\ University of Economics - Varna, Varna, Bulgaria \\ krasimira_yancheva@ue-varna.bg \\ Chief Assistant, PhD Todor Dyankov \\ University of Economics - Varna, Varna, Bulgaria \\ todordyankov@ue-varna.bg
}

\begin{abstract}
The article reflects certain outcomes from the current research process within the project Silk Road Local Culture - SILC which is conducted under the Joint Operational Programme Black Sea Basin 2014-2020. The SILC project is still on elaboration by the research partners from Armenia, Bulgaria, Georgia, Greece and Romania. The authors of the article represent the research team on the Bulgarian side and have already prepared some preliminary study according to the project requirements. In this relation the eastern part of destination Bulgaria has become the focal territory of the research scope. For that reason the main purpose of this article is to outline the strategic opportunities resulting from the SILC Road local culture project for destination Bulgaria based on successfully implemented good international practices.
\end{abstract}

Keywords: Silk Road, cultural heritage, tourism masterplan, tourism destination, Bulgaria

JEL Code: Z300; doi:10.36997/IJUSV-ESS/2019.8.3.81

\section{Въведение}

Със своето богато културно-историческо наследство страните на Пътя на коприната разкриват значим потенциал за съвместно туристическо развитие чрез създаване на интегрирани туристически продукти. Международни организации като ЮНЕСКО, Световната организация по туризъм (СОТ) и Европейският съюз (ЕС) работят активно за създаване на мрежи от заинтересовани страни за туристическа валоризация на темата „Пътят на коприната“".

Проектът „Местната култура по пътя на коприната“ (“SILC Road local culture”) се реализира по Съвместна оперативна програма „Черноморски басейн 2014 - 2020“ с период на изпълнение 2018-2021 г. Партньори по проекта са: Университет Аристотел / Солун, Икономически университет - Варна, Руско - Арменски университет (Армения), Международен център за социални изследвания и политически анализи (Грузия) и Национална асоциация за селски, екологичен и културен туризъм / Тулча (Румъния). Предназначението на проекта е да се идентифицира, оцени, картографира и промотира културното наследство на Пьтя на коприната, което да се използва за туристическото развитие на районите, попадащи на древния търговски път.

Целта на настоящата статия е да се очертаят произтичащите от проекта „Местната култура по пътя на коприната“ стратегически възможности за дестинация България в контекста на реализираните добри международни практики за използване на културноисторическото наследство по Пьтя на коприната за нуждите на туризма.

\section{1. Пътят на коприната в туристически контекст}

В туристически контекст Пътят на коприната е един от най-интересните и посещавани туристически маршрути, който се отличава с многобройни паметници на културно- 
историческото наследство (КИН), много от който са включени в списъка на ЮНЕСКО. Древният тьрговски път днес е изпъстрен с градове, музеи, природни забележителности, различни национални култури, традиции, бит, фолклор и кулинария, които привличат туристи с различни интереси от различни страни.

Пътят на коприната не е „един единствен път”, а мрежа от пьтища, включващи много и различни дестинации в различни държави. Красотата на Пьтя на коприната се крие в това, че той е транснационален маршрут, който се простира на три континента и обхваща 33 държави. Дестинации като Китай и други държави в Централна Азия работят отдавна върху концепцията за Пътя на коприната като възможност за туристическо развитие. България също се приобщава към инициативата.

Хронологията на проектната дейност за туристическите маршрути по Пьтя на коприната показва, откога, как и кои заинтересовани страни използват потенциала на древния път между Китай и Европа, Азия и Африка за развитието на туризма.

През 1988 г. ЮНЕСКО стартира десетгодишен проект, озаглавен „Интегрално проучване на пътищата на коприната: пътища на диалога“. Той включва конкретни действия за всестранно изучаване на историята на древните маршрути и установяване на тесни контакти и партньорство между Изтока и Запада. Целта на проекта е провеждане на полеви проучвания по тези маршрути с оглед стимулиране на по-нататъшни изследвания в международен и национален план и подчертаване на сложните културни взаимодействия, произтичащи от срещите между Изтока и Запада (UNESDOC, 2019). Пътя на коприната свързва цивилизации и среща хора и националности от цял свят в продължение на хиляди години, позволявайки не само размяна на стоки, но и взаимодействие на идеи и култури. За разпространението им е разработена Онлайн платформата на ЮНЕСКО "Пътят на коприната", чиято цел е да съживява и разширява тези исторически мрежи в дигитално пространство, обединявайки хората в непрекъснат диалог за Пътя на коприната (ЮНЕСКО, 2019).

През 1993 г. на заседание на Генералната асамблея на ООН в Индонезия е прието решение за възраждането на Пътя на коприната като важен канал за международно сьтрудничество в областта на икономиката, дипломацията, културата, науката, тьрговията и туризма. Концепцията цели обединяване на древните маршрути в един проект, обхващащ над 12000 км. маршрут. (СОT, 2019).

През 1994 г. СОТ съвместно с ЮНЕСКО провежда в Узбекистан първото международно заседание „Великият пъm на коприната”, където 19 страни приемат известната Самаркандска декларация за развитие на легендарното трасе като транснационален туристически маршрут. През 1996 г., на международния форум на СОТ в Сиан (Китай) е приет новият маркетингов план, подписан от всички страни-участнички. Присъстват представители на ЮНЕСКО и ПРООН, 110 водещи мениджъри на туристически компании, учени и журналисти от над 25 страни, туроператори, собственици на най-големите хотелски вериги. В Сиан, СОТ за първи път получава възможността да помогне на страните по древния път като установи реални делови контакти с туроператорите от основните международни пазари. Дейностите на СОТ по Пьтя на коприната за периода 1993-2011 г. са както следва: (СОТ, 2019):

$>1993$ Генерална асамблея Пьтя на коприната / Бали / Индонезия (Silk Road Project General Assembly Bali, Republic of Indonesia);

$>1994$ Първа международна среща Пътя на коприната / Самарканд / Узбекистан (First International Silk Road Meeting Samarkand, Republic of Uzbekistan);

$>1995$ Събития Пътя на коприната / Световна туристическа борса Лондон и ITВ Берлин (Silk Road Events 1994/95: World Travel Market London and at ITB Berlin);

$>1996$ Пьрви туристически форум Пътя на коприната / Китай (First Silk Road Travel Forum Xi'an, People's Republic of China); 
$>1997$ Втори туристически форум Пътя на коприната / Нара / Япония и други сродни събития през годината (Second Silk Road Travel Forum Nara, Japan, Second International Silk Road Meeting Tehran, Islamic Republic of Iran International Silk Road Meeting on Tourism and the Environment Bishkek, Kyrgyz Republic, UNWTO General Assembly Workshop Istanbul, Republic of Turkey);

$>1998$ Трети туристически форум Пътя на коприната / Киото / Япония и други сродни събития през годината (Third Silk Road Travel Forum Kyoto, Japan,Silk Road Tour Operators Workshop Almaty, Republic of Kazakhstan, Third International Silk Road Meeting Tbilisi, Georgia);

$>1999$ СТО / ЮНЕСКО Туризъм и култура - семинар / Кива / Узбекистан (WTO/UNESCO Tourism and Culture Seminar Khiva, Republic of Uzbekistan);

$>2002$ Четвърта международна среща Пътя на коприната / Букхара / Узбекистан (Fourth International Silk Road Meeting Bukhara, Republic of Uzbekistan);

$>2003$ Семинар на Генералната асамблея на СТО / Пекин / Китай и други сродни събития през годината (UNWTO General Assembly Workshop Beijing, People's Republic of China; 2004 The Silk Road Initiative (SRI), The UN Silk Road City Awards);

$>2006$ Първи инвестиционен форум Пътя на коприната / Китай (First Silk Road Investment Forum Xi'an, People's Republic of China);

$>2009$ Среща на Генералната асамблея на СТО Пътя на коприната / Астана / Казахстан (UNWTO General Assembly Silk Road Meeting Astana, Republic of Kazakhstan);

$>2010$ Форум на кметовете Пътя на коприната / Шираз / Иран и други сродни събития през годината (Shiraz Silk Road Mayors Forum Shiraz, Islamic Republic of Iran, Fifth International Silk Road Meeting Samarkand, Republic of Uzbekistan);

$>2011$ Среща на върха на министрите Пътя на коприната ITB Берлин (Silk Road Ministers' Summit at ITB Berlin 2011 Berlin, Federal Republic of Germany 9-13 March);

Инициативи на ЮНЕСКО и СОТ и проекти като: Дестинации Пътя на коприната (Silk Road Destinations), Трансатлантически съюз Пътя на коприната (Silk Road Transatlantic Alliance, както и Пътническа асоциация Пътя на коприната (Silk Road Travel Association), Мрежа Пътя на коприната (Silk Road Network), инвестират в уникалния древен път като възможност за засилване на международното сътрудничество в областта на културата, търговията, туризма и науката. Проектната дейност на СОТ по Пьтя на коприната за периода 2012-2018 година включва следните теми (СОТ, 2019):

$>2012$ Морският път на коприната в 21 век - възможности за туризъм и въздействия, СТО (The 21st Century Maritime Silk Road - Tourism Opportunities and Impacts, UNWTO / Pilot Productions joint collaboration: Globe Trekker Round the World 20th Anniversary Special, EHL/UNWTO Silk Road Strategy Challenge 2012, EHL/UNWTO Silk Road Strategy Initiative);

> 2013 Стратегия за управление на хотелиерството / СТО и други сродни инициативи (UNWTO / EHL Altai Krai Hospitality Management Strategy, Русский - ЮНВTO/ Школа Гостиничного Менеджмента: Разработа стратегии гостиничного менеджмента Алтайского края, UNWTO / WTM Silk Road Bloggers Trip to Armenia, UNWTO / UNESCO Silk Road Heritage Corridors Tourism Strategy Project, Рабочее совещание ЮНЕСКО/ЮНВТО по коридорам наследия Шелкового пути);

2014-2016 Проект VeRoTour и други сродни инициативи (VeRoTour Project; 2015- First ever Silk Road training course for heritage guides taking place in Khiva, Uzbekistan; 2016- 'David Baddiel on the Silk Road' to air on Sunday 21 February at 9pm on the Discovery Channel UK, BBC documentary on the Silk Road hosted by renowned historian Dr. Sam Willis, Western Silk Road Tourism Initiative, Enhancing Silk Road Interpretation and Quality Guide Training, UNWTO Workshop for Inbound Tour Operators);

> 2017-2018 Университетско предизвикателство Западния път на коприната (Western Silk Road University Challenge, UNWTO Silk Road Training and Capacity Building 
Programme).

Важна роля за възраждането и популяризирането на древния път има COT, чрез реализацията на регионалния проект „Дестинации по Пътя на коприната“ (Silk Road Destinations) (Silc Road Travel, 2019). Той обединява туроператори от девет различни държави по Пътя на коприната (Армения, Грузия, Азербайджан, Туркменистан, Узбекистан, Таджикистан, Киргизстан, Казахстан и Китай (Синдзян)), в съвместни усилия за популяризиране на туристически продукти по Пьтя на коприната в по-широк международен контекст. Основната цел на проекта „Дестинации по Пътя на коприната“ е: „организиране и популяризиране на международните пазари на различни съвместни многонационални обиколки по Пътя на коприната на възможно най-високо ниво по отношение на качеството и на достьпни цени”. Мащабни туристически проекти като „Международно автомобилно рали“ (International Auto Motor Rally) и „Многонаџионални турове” (Multinational tours) допълнително спомагат за международното промотиране на Пътя на коприната.

„Дестинации по Пътя на коприната“" (Silk Road Destinations) предоставя възможност за изживяване на културата по Пьтя на коприната чрез участие в социални събития, в културни тържества и шоу програми.

Културните маршрути като средство за развитие на устойчив туризъм са в центъра на дискусиите на министрите на страните членки в програмата „Пътя на коприната“. Министерска среща, в която участва тогавашният заместник-министьр на икономиката, енергетиката и туризма Иво Маринов е част от програмата на най-голямото туристическо изложение в света - ITB, Берлин. В срещата участва и генералният секретар на Световната организация по туризъм Талеб Рифай (THEEXPERTS, 2019). Европа разполага с една от найобширните мрежи от културни туристически маршрути в света, което осигурява сериозно предимство на стария континент за развитие на устойчив туризъм с акцент върху конкурентоспособността и иновациите. Затова през юни 2010 г. СОТ създава първия план за действие по програмата „Пътят на коприната“ с акцент върху маркетинга и промоцията на туристическите маршрути, изграждане на капацитет и мениджмънт на дестинациите.

България работи по няколко транснационални туристически проекта като координатор и партньор. Заедно с Хърватия, Сърбия и Румъния нашата страна е координатор по проекта „Пътя на римските императори“, кооперирана е и с още пет балкански държави в проекта „Пътя на желязната завеса“. Всички тематични туристически маршрути, които развива, са насочени към нарастване на туристическата привлекателност на района, диверсификация на туристическия продукт и повишаване конкурентоспособността на отрасъла.

България членува в програмата на СОТ „По пътят на коприната“ от 2012 г. София е домакин на Втория международен семинар „По Западния Път на коприната“, проведен в рамките на „Инициативата за развитие на туризма по Западния Пьт на коприната“ през 2017. Това е съвместен проект на СОТ и Европейската комисия и е част от европейската инициатива „Подобряване на разбирането за европейския туризъм“. Чрез реализирането на този проект се цели популяризиране на възможностите за осъществяване на туристически дейности по западните участьци на Пьтя на коприната. Една от основните идеи на инициативата е да бъдат обособени туристически маршрути по „Западния Път на коприната“, а в дългосрочен план се очаква това да доведе до интензифициране на транснационалното сътрудничество между страните, членуващи в програмата на СОТ „По Пътя на коприната““ (Министерство на туризма, 2019).

България си сътрудничи с Гърция в реализацията инициативата „По Западния Път на коприната“", свързана с привличане на посетители от далечните за Европа пазари. България и Гьрция са членове на програмата на СОТ „По Пьтя на коприната“. През 2017 г. те са домакини на два работни семинара по новата инициатива „Западния път на коприната““ и участват в създаването на Пътна карта по проекта чрез национални анализи. Българското 
предложение визира създаване на регионални продукти, свързани с коприната, например чрез консолидиране на туристическия потенциал на гръцки и български градове с традиции като Софлу и Ивайловград (СЕГА АД, 2019).

\section{2. Характеристики на проекта SILC - цели, дейности, очаквани резултати}

Проектьт „Местната култура по Пътя на коприната“, "SILC Road local culture” (SILC) като част от Съвместна оперативна програма „Черноморски басейн 2014 - 2020“, продължава инициативата на Световната организация по туризъм (UNWTO) за развиването на Западния Път на коприната посредством туризма от зоната на Каспийско и Черно море през Балканския полуостров в направление Средиземноморие и Западна Европа. Необходимостта от поставянето на проекта SILC ce обосновава от една страна от наличието на множество ресурсни дадености с потенциал за разгръщането им в специфични активи чрез съвместни координирани инициативи, а от друга - тяхното недостатъчно популяризиране в системата на културния туризъм. В тази връзка и основните очаквания по проекта SILC са свързани със стимулирането на нови бизнес възможности в туризма на фона на нарастващия туристически пазар по Пьтя на коприната. Възобновяването на Пътя на коприната в съвременен аспект се основава на отчитането на нов вид туристически потоци от индивидуални посетители, търсещи интеракция с различни местни култури извън спектъра на масовия туризъм. Оттук може да се подчертае, че главната цел на проекта SILC е да се зададе стратегически подход за промотиране на туристическите продукти по Пътя на коприната в рамките на Европейския съюз и страните от Черноморския басейн. За изпълнението на тази цел е необходимо да се анализира неразкрития потенциал на местното културно наследство по Пътя на коприната в споменатия регион, както и да се откроят перспективите за създаване на нови предприемачески мрежи в туризма, обвързани в обща маркетингова и управленска стратегии.

Както беше споменато проектът SILC се разработва от екип от представители на три висши учебни заведения и две бизнес организации, опериращи съответно в туристическите дестинации - бенефициенти от Черноморския басейн. Основните резултати относно изпълнението на целите на проекта са предвидени да бъдат финализирани към месец май 2021 г. В процеса на разработването на проекта, партньорите се задължават да изготвят както доклади за съвместни резултати, така и да допринесат със специфични дейности по осъществяване на етапите на проекта SILC.

В частта Балкански полуостров проектът SILC засяга териториални части от Румъния и България в така наречения Дунавски макрорегион. По тази географска ос България със своите Североизточен и Югоизточен район се явява ключов елемент на директна връзка по Пътя на коприната между Румъния и Гърция от една страна, както и в индиректен, отвъдморски обмен с дестинациите Армения и Грузия. Основната идея за прокарването на тази отсечка по Пътя на коприната е засилването на социално икономическото взаимодействие на Източната част на Европейския съюз (Румъния, България, Гърция) със страни партньори извън общността - Армения и Грузия. В този аспект проектът SILC тясно кореспондира със следните предхождащи го инициативи, като: Инициативата Западния Път на коприната (Western Silk Road Initiative UNWTO / EU) стартирала през 1993 г. под егидата на COT, която през 2016 г. в сътрудничество с EC е трансформирана като ключова програмата от Инициативата за туристическото развитие по Западния Път на коприната (Western Silk Road Tourism Development Initiative); Проект за стратегия за туризма в културните коридори по Пътя на коприната (Silk Road Heritage Corridors Tourism Strategy Project UNWTO / UNESCO, 2014) чийто фокус пада върху два културни коридора, пресичащи пет държави: Китай, Казахстан, Киргистан, Таджикистан и Узбекистан; Предизвикателство на блогърите по Пътя на 
коприната, 2012 (Silk Road Bloggers Ch@llenge 2012 UNWTO / WTM) - събитие организирано в Армения с основна цел усилване процеса на популяризиране на Пътя на коприната в социалните медии и онлайн пространството; Черноморска мрежа за устойчив туризъм (Black Sea Network for Sustainable Tourism BS NTS) - стимулираща създаването на стратегии за съвместен маркетинг и икономическо развитие в Черноморския регион.

Проектът SILC като част от Съвместната оперативна програма „Черноморски басейн 2014 - 2020“ е в съответствие и с приоритетите от „общите резултативните индикатори", заложени в Европейския инструмент за трансгранично сътрудничество между съседите 2014 - 2020 (European Neighbourhood Instrument for Cross - border Cooperation), като:

$>\quad$ Усилване на трансграничните бизнес възможности в областта на туризма и културата;

$>$ Усилване на трансграничните връзки за търговия и модернизация на селското стопанство и свързаните с него сектори;

Установяване на равнище на сравнимост на данните и информация от провеждан трансграничен мониторинг;

$>\quad$ Повишаване нивото на осъзнатост относно предизвикателствата от околната среда и добрите практики в управлението на отпадните процеси при речното и морско замърсяване;

туризма;

Развиване на стратегии и продукти с цел съвместно промотиране на

$>\quad$ Организиране на трансгранични туристически и културни събития;

$>$ Извършване на подобрения на малки по размер културни и исторически места, забележителности и др.;

В процеса на разработване на проекта SILC са заложени следните стъпки (фази):

I. Осъществяване на базово проучване

II. Създаване на предприемаческа мрежа по местния Път на коприната (SILCNET network)

III.Създаване на виртуална обсерватория

IV. Изготвяне на ръководство (наръчник) за сертифициране и налагане на знака SILCNET label

V. Комуникация на проекта SILC

Базовото проучване по проекта включва ангажимент на всеки един от партньорите да изготви подробна оценка на местното културно наследство по Пьтя на коприната в съответната страна; да подготви информация за изготвяне на карта на въпросното културно наследство и да оцени потенциала за неговия туристически и икономически растеж. В тази връзка местното материално и нематериално културно наследство по Пьтя на коприната следва да се открои (диференцира) от общите туристически ресурси в дестинацията. Оттук неговото промотиране, диверсифициране и развиване на междурегионално равнище се явяват основни задачи пред заинтересованите страни бенефициенти.

Информацията за картографирането служи като основа при изграждане на ГИС (географска информационна система) чийто краен резултат е създаването на интерактивна карта, която визуално да предоставя подробна информация за местоположение, големина, исторически данни и други характерни особености на местното културно наследството по Пътя на коприната. Тази проектна дейност се разработва в три направления: идентификация и регистрация на местното културно наследство по Пътя на коприната; създаване на профили на местното културно наследство, както и на профили на съответните заинтересованите страни, желаещи да се включат под знака SILC. Продуктите от картографирането и профилирането служат като входяща информационна банка за така наречената виртуална 
обсерватория.

Оценката на потенциала на туристическия и икономически растеж на местното културно наследство по Пътя на коприната включва разработването на ситуационен анализ на изследвания район с ключови стъпки по инвентаризация на туристическия ресурсен потенциал, оценката на общата и туристическа инфраструктура, правния и политически контекст, местните заинтересовани страни, както и спецификите на туристическото търсене. Ситуационният анализ предпоставя определяне и на силата на туристическия интерес за посещения на изследвания район, както и степента на съгласуване на вижданията на всички заинтересовани страни.

Като краен резултат от базовото проучване се планира изготвянето на стратегическа рамка за усвояване на потенциала за туристически растеж на местното културно наследство по Пътя на коприната, ориентирана към:

$>$ популяризиране на разнообразни местни туристически продукти, относно които местните заинтересовани страни могат да се обединят и да ги промотират на пазари със специални интереси;

$>$ създаване на междурегионални туристически продукти по Пътя на коприната и общи стандарти за обслужване;

$>$ обмяна на опит и разпространение на добри практики чрез насьрчаване на развитието на културния туризъм;

$>$ интензифицирането на нивото на сьтрудничество и управленските компетенции на местния бизнес по въпросите на културния туризъм;

$>$ популяризиране на приноса на изследваните райони за укрепването на предприемачеството по Черноморския път на коприната;

Насоките от стратегическата рамка служат за създаване на общ мастерплан за трансгранично сътрудничество, който акцентира върху развитието на местното културно наследство по Пътя на коприната с два времеви хоризонта - от 2 и от 5 години.

Дейността по създаването на предприемаческа мрежа по местния Път на коприната (SILCNET) цели навлизането на нови туристически пазари и пазарни сегменти чрез използване на предимствата от мастерплана за изследваните райони заедно с приемането на общ стратегически маркетингов план. В тази насока се предвижда мрежата SILCNET от една страна да бъде технически свързана с други местни и междурегионални мрежи от Черноморския басейн, а от друга - функционално обвързана с регионални правителствени и неправителствени организации. Основното очакване от споделянето на съвместен стратегически маркетингов план е промотирането на диверсифициран туристически бранд, адаптиран към местното културно наследство чрез подобряване на имиджа и ефективността на маркетинговите усилия по Пьтя на коприната. За успешното реализиране на SILCNET мрежата се откроява следния списьк от изискуеми резултати:

$>$ изграждането на бази от данни за участниците в мрежата, включваща обща и разширена информация за партньорите предприемачи, поддържана и обновявана онлайн през виртуалната обсерватория;

$>$ изготвяне на матрица за участниците в мрежата - с цел получаване на по-голяма яснота относно тяхното влияние в мрежата, техния динамичен потенциал, ангажирането и въвличането им в съответните процеси;

$>$ разработване на обща маркетингова стратегия, включваща съвместен стратегически маркетингов план и ръководство с базови насоки и добри практики за прилагането на проекта SILC;

Основните мотиви за създаването на виртуалната обсерватория са: предоставянето на информационна платформа за туристическата индустрия, академичните среди, управленските организации, други бизнеси и туристи чрез споделянето на надеждни, сравними, обновяеми данни за пазара на културното наследство по Пътя на коприната, за 
промените и тенденциите в неговото развитие. Залага се на развиването на своего рода разузнавателен център по Пьтя на коприната, чрез който да се събират и споделят всички публикации от бизнеса и академичните среди през специално организирана виртуална библиотека относно вид туризъм, държава, тематика и други параметри на търсене. В качеството на ключов продукт от виртуалната обсерватория се предвижда и създаването на уеб базирано приложение за разпознаване на SILC местоположение, както на английски език, така и на всички партньорски езици. Посредством това приложение, вече визуализираните членовете от мрежата на интерактивната уеб - базирана ГИС карта към виртуалната обсерватория, могат да бъдат и клъстерно идентифицирани от гледна точка на туризма. Главните дейности предвидени в процеса на създаването на обсерваторията включват: разработването на дизайн на онлайн платформа, като многоезичен уеб - базиран ГИС портал, инкорпориращ в себе си възможностите на мобилните приложения за интеракция и споделяне на преживявания от всички; създаването на уеб - базирано ГИС хранилище на данни; осигуряването и мониторинг на отворен геопространствен консорциум, който да поддържа географски замервания, предварително дефинирани пространствени и атрибутивни заявки със съответните символи, интерактивно съдържание и други интерактивни функции; входиране на съдържанието на данните идващи от партньорските дестинации; документиране на разкази и истории от етногеографско естество, предоставени от местните общности по Пьтя на коприната.

Идеята за създаването на знака SILCNET се базира на множество разработени практики към програми от ЕС, която намира израз в следните проявления: изграждането на стабилни връзки между SILC предприемачите; подобряване осведомеността за маршрути по местния Пьт на коприната; формиране на добра разпознаваемост и принадлежност на всеки SILC предприемач към мрежата от партньори и увеличаване на възможностите за тяхната конкурентоспособност; установяване и институционализиране на перманентно сьтрудничество между всички заинтересовани страни; оптимизиране управлението на капацитетните възможности на местно ниво; промотиране и подкрепа на малкия и среден бизнес в местния културен туризъм. В сърцевината на реализирането на знака SILCNET проектьт предвижда провеждането на съвместни трансгранични тренировъчни програми в партньорските дестинация. Отговорен участник за осьществяването на тази основна проектна дейност е българската страна. За целта се планира:

$>$ изготвяне на доклад за проучване на възможностите за реализиране на знака SILCNET. Документът трябва да даде практически отговор на въпроса по какъв начин мрежата SILCNET, виртуалната обсерватория и знакът SILCNET ще продължат да съществуват след приключването на проекта;

създаване на SILCNET лого, което да интегрира всички сертифицирани членове от партньорските държави в SILCNET мрежата, както и промоционални материали с цел привличане на нови предприемачи;

$>$ изготвяне на учебни материали за сертификационния знак SILCNET, адаптирани според потребностите на местните общности от партньорските държави;

$>$ подготовка на тренировъчни курсове за приемане на знака SILCNET;

$>$ организиране на пилотно изпълнение на частта от проекта за приемане на знака SILCNET между партньорите;

$>$ създаване на дългогодишни споразумения за партньорство между участващите страни извън сферата на джоинт венчърите;

Комуникацията на проекта SILC се предвижда да бъде осъществена в няколко направления:

$>$ създаване на дизайн на лого на проекта;

$>$ определяне на основните целеви групи за комуникиране на проекта;

$>$ всеобхватно използване на социалните медии за комуникиране на текущите и 
приключили проектни дейности;

$>$ създаване на комуникационен план на проекта с интегрирана комуникационна система, която ефективно да отразява проектните резултати между всички заинтересовани страни от партньорските дестинации;

$>$ планиране на комуникационни инициативи и инструменти за комуникацията на проекта SILC - уебсайт на проекта; електронен бюлетин; брошура, плакат (банер) на проекта; прес съобщения; научни публикации; наръчник на проекта; участие в конференции; събития на местно, национално и международно равнище, уебинар за приемане на знака SILCNET; организиране на „Роуд шоу” на местното културно наследство по Пьтя на коприната и др.

От характеристиките на проекта SILC стават нагледни и разкриващите се възможности за туристическа дестинация България, а именно чрез нейното пълно културно и икономическо интегриране към Пътя на коприната на всички социални и управленски равнища; допринасяне на нови положителни трансформации към масовия ваканционен туризъм; подобряване на маркетинговото позициониране на дестинация България на международните туристически пазари; развиване на устойчива конкурентоспособност в среда на динамични и турбулентни конюнктурни процеси.

\section{Заключение}

Реализирането на Проекта „Местната култура по пътя на коприната“ (“SILC Road local culture”) ще доведе до повишаване на интернационализацията, свързаността и конкурентоспособността на заинтересованите страни предимно в източните части на дестинация България в областта на устойчивия културно-познавателен туризъм.

Информационната система на дестинацията ще се обогати с идентифицирани, регистрирани, паспортизирани и картографирани материални и духовни обекти на местното културно наследство по Пътя на коприната с потенциал за туристическа валоризация.

Туристическа дестинация България ще получи пространствено-културен хоризонт и приоритети за туристическо развитие чрез разработваната стратегическа рамка за усвояване на потенциала за туристически растеж на местното културно наследство по Пьтя на коприната в Черноморския регион, а в по-широка перспектива и в културно-туристическото пространство на Каспийско и Черно море през Балканския полуостров в направление Средиземноморие и Западна Европа.

Планираната предприемаческа мрежа SILCNET ще осигури свързаност на заинтересованите страни в дестинация България с други местни и междурегионални мрежи от Черноморския басейн, като по този начин ще се създадат възможности за нови устойчиви туристически бизнес практики.

Туристическа дестинация България ще присъства във виртуалната обсерватория, която ще обслужва информационно туристическата индустрия, академичните среди, управленските организации, други бизнеси и туристи чрез споделянето на надеждни, сравними и актуални данни за състоянието и тенденциите на туристическия пазар на културното наследство по Пътя на коприната.

Туристическите предприемачи в дестинация България ще могат да се възползват от маркетинговия ефект на сертификационния знак SILCNET. Носителите на знака ще участват в създаването на стабилни връзки между SILC предприемачите. Ще получават добра осведомеността за маршрути по местния Път на коприната. Ще се ползват от формирането на добра разпознаваемост и принадлежност на всеки SILC предприемач към мрежата от партньори. Установеното и институционализирано чрез знака SILCNET перманентно сътрудничество между заинтересованите страни ще доведе до по-добро управление на капацитетните туристически възможности на местно ниво, както и до промотиране и подкрепа на малкия и среден бизнес в местния културен туризъм. 


\section{References}

1. Ministry of tourism. Republic of Bulgaria. (2019) [Online] Available from: http://www.tourism.government.bg/bg/kategorii/novini/ministur-angelkova-uchastva-berlin-vdevetata-ministerska-sreshta-za-proekta-po.

2. Ministry of tourism. Republic of Bulgaria.Ministar Angelkova: Balgaria i Gartsia si partnirat po savmestni proekti za privlichane na turisti ot dalechni pazari kam Balkanite. (2019) [Online] Available from: http://www.tourism.government.bg/bg/kategorii/novini/ministur-angelkovabulgariya-i-gurciya-si-partnirat-po-suvmestni-proekti-za.

3. SEGA AD. Tourism. Patyat na koprinata stava turisticheski marshrut. (2019) [Online] Available from: http://old.segabg.com/article.php?id=318674. [Accessed 14/04/2019].

4. Alexieva, Sonya . The silk road as a tourist product: integrating history, culture and economy. New Bulgarian University. (2019) [Online] Available from: http://eprints.nbu.bg/2008/27/Pages\%20from\%20TheSilkRoad2011.pdf [Accessed 9/09/2019].

5. Bloomberg TV Bulgaria. Patyat na koprinata e bil internetat na drevnostta. (2019) [Online] Available from: https://www.bloombergtv.bg/v-razvitie/2017-06-27/patyat-na-koprinata-e-bilinternetat-na-drevnostta. [Accessed 27/06/2019].

6. SilkRoad.Travel. Silk Road Destinations. (2019) [Online] Available from: http://www.silkroad.travel/ [Accessed 14/09/2019].

7. THEXPERTS. Patyat na koprinata e v tsentara na diskusiite na turisticheskite ministri v Berlin. (2019) [Online] Available from: https://thexperts.bg/article/,пътят-на-коприната“-е-вцентъра-на-дискусиите-на-туристическите-министри-в-берлин. 7.03.2012, [Accessed 16/09/2019].

8. UNESCO. The UNESCO Silk Roads Project. (2019) [Online] Available from: https://en.unesco.org/silkroad/unesco-silk-road-online-platform, [Accessed 12/08/2019].

9. UNESDOC. (2019) [Online] Available from: https://unesdoc.unesco.org/ark:/48223/pf0000159189, [Accessed 12/08/2019].

10. UNESDOC. The Silk Roads Project: Integral study of the Silk Roads: Roads of Dialogue, 1988-1997, (2019) [Online] Available from: https://unesdoc.unesco.org/ark:/48223/pf0000159189, [Accessed 12/08/2019].

11. UNWTO(2019) [Online] Available from: http://silkroad.unwto.org/content/silk-road-projects

12. UNWTO (2019) [Online] Available from: http://silkroad.unwto.org/sites/all/files/docpdf/bannerhistorywebsite.pdf, [Accessed 13/08/2019].

13. UNWTO Silk Road projects, (2019) [Online] Available from: http://silkroad.unwto.org/content/silk-road-projects, [Accessed 12/08/2019].

14. UNWTO. Summary of Silk Road Activities 1993-2011. (2019) [Online] Available from: http://silkroad.unwto.org/sites/all/files/docpdf/summaryofactivities1993-2011.pdf, [Accessed 15/08/2019].

15. UNWTO. Western Silk Road Tourism Initiative, (2019) [Online] Available from: http://silkroad.unwto.org/project/western-silk-road-tourism-initiative, [Accessed 16/08/2019].

16. Ureport.bg. Kitai pravi fond ot Китай $\$ 16.3$ mlrd. za Patya na koprinata, (2019) [Online] Available from: https://ureport.bg/41176/2014/11/04/ikonomika/kitay-pravi-fond-ot-16-3mlrd-za-patya-na-koprinata 4.11.2014. [Accessed 20/09/2019].

Вътрешни документи по проекта:

17. D.T1.1.4 Guidelines for the study

18. Silk Road Local Culture - SILC: Joint Operational Programme Black Sea Basin 2014 - 2020, Subsidy Contract No. 99372/31-08-2018 